\title{
Parasitismo por Lernaea cyprinacea em Astyanax bimaculatus provenientes de um açude no município de Antonio Prado, Rio Grande do Sul
}

\author{
Parasitism by Lernaea cyprinacea in Astyanax bimaculatus \\ from a dam in the municipality of Antonio Prado, Rio Grande do Sul \\ Miguel Gallio ${ }^{1}$, Aleksandro Schafer da Silva ${ }^{1} \&$ Silvia Gonzalez Monteiro ${ }^{2}$
}

\begin{abstract}
RESUMO
A Lernaea cyprinacea é um crustáceo copépode que causa lesão no tegumento do peixe, o que acarreta um aspecto repugnante. Esse fator inviabiliza o peixe para consumo humano, trazendo prejuízos para a piscicultura. O objetivo deste estudo foi relatar o parasitismo por L. cyprinacea em Astyanax bimaculatus (lambari). Foram necropsiados vinte peixes provenientes de um açude da região nordeste do Rio Grande do Sul. Os parasitos foram removidos manualmente, montados em lâmina de vidro e identificados baseando-se nas características morfológicas da fêmea. Todos os peixes analisados apresentavam-se parasitados pelo copépode L. cyprinacea. Os lambaris apresentavam lesões no local de fixação dos parasitos, possivelmente devido ao grande número de crustáceos por peixe. Observou-se nos lambaris uma infestação de 12-39 parasitas. É preocupante a presença do verme âncora em um ambiente natural da região, pois essa espécie exótica pode disseminar-se e parasitar outras espécies de peixes.
\end{abstract}

Descritores: Lernaea cyprinacea, Astyanax bimaculatus, copépode, piscicultura.

\section{ABSTRACT}

The Lernaea cyprinacea is a crustacean copepods that causes lesion in the tegument of the fish, which, consequently, it carts a repugnant aspect. That factor makes unfeasible the fish for human consumption, bringing damages for the fish farming. The aim of the present work was to report the parasitism by Lernaea cyprinacea on Astyanax bimaculatus commonly named lambari. Twenty fish specimens from a dam at the Northeast region of the Rio Grande do Sul were analyzed. The parasites were manually removed and identified based on female morphological characteristics. All the analyzed fish were parasitized by $L$. cyprinacea. In the region of attachment it was observed lesions. It was observed in the characin an infection of 12-39 parasites. It brings concern the occurrence of the anchor worms in a natural environment because this exotic species is able to spread and to parasitize other species of fishes.

Key words: Lernaea cyprinacea, Astyanax bimaculatus, copepod, fish farming. 


\section{INTRODUÇÃO}

Os peixes do gênero Astyanax sp., popularmente conhecidos por lambari se fazem presentes em todas as bacias hidrográficas do Rio Grande do Sul e de outros estados do Brasil, sendo fundamentais no equilíbrio ecológico do habitat em que estão inseridos devido aos seus hábitos alimentares onívo$\operatorname{ros}[4,5,16]$.

Lernaea cyprinacea é um crustáceo copépode, encontrado na maioria das regiões brasileiras parasitando diferentes espécies de peixe [13]. Segundo a Associação dos Zootecnistas do Paraná, a L. cyprinacea é cosmopolita e parasita Carassius carassius (carpas) e outras 45 espécies de peixes [2].

$\mathrm{O}$ ciclo da $L$. cyprinacea desenvolve-se em três estádios de nauplius e cinco estádios de copepoditos, que quando se diferenciam sexualmente passam a se chamar cyclopoides. O macho, após fecundar a fêmea de vida livre morre, e esta, passa a parasitar perfurando a pele e fixando-se no tecido muscular dos peixes onde desenvolve um órgão parecido com uma âncora [6]. Segundo a literatura, o formato dessa âncora é a característica taxonômica mais importante para identificação do gênero [7], sendo variável de acordo com seu crescimento e orientação, podendo ter sua forma afetada pelo encontro com o tecido ósseo e outros tecidos duros no interior do hospedeiro.
Por suas capacidades adaptativas, os integrantes do gênero Lernaea sp. possuem resistência aos tratamentos convencionais em seu estádio adulto, já que sendo um crustáceo, possui um exoesqueleto de quitina que o torna um parasito de difícil controle [18]. Devido a importância deste parasito, julgou-se oportuno relatar o parasitismo por L. cyprinacea em Astyanax bimaculatus em ambiente natural.

\section{MATERIAIS E MÉTODOS}

Foram necropsiados 20 peixes provenientes de um açude natural da região nordeste do Rio Grande do Sul, município de Antônio Prado. Os parasitos foram coletados manualmente, lavados e conservados em solução de Railliet-Henry. No Laboratório de Parasitologia Veterinária da Universidade Federal de Santa Maria os copépodes foram clarificados com ácido lático, colocados em uma gota de meio de Hoyer [8], montados em lâmina de microscopia e identificados segundo literatura [9].

\section{RESULTADOS}

Todos os peixes analisados estavam parasitados por L. cyprinacea (Figura 1), sendo observado nos lambari uma infestação de 12 a 39 crustáceos/peixe. Os parasitos ao se fixarem nos peixes, ocasionaram lesões locais, onde se desenvolveu infecção bacteriana,

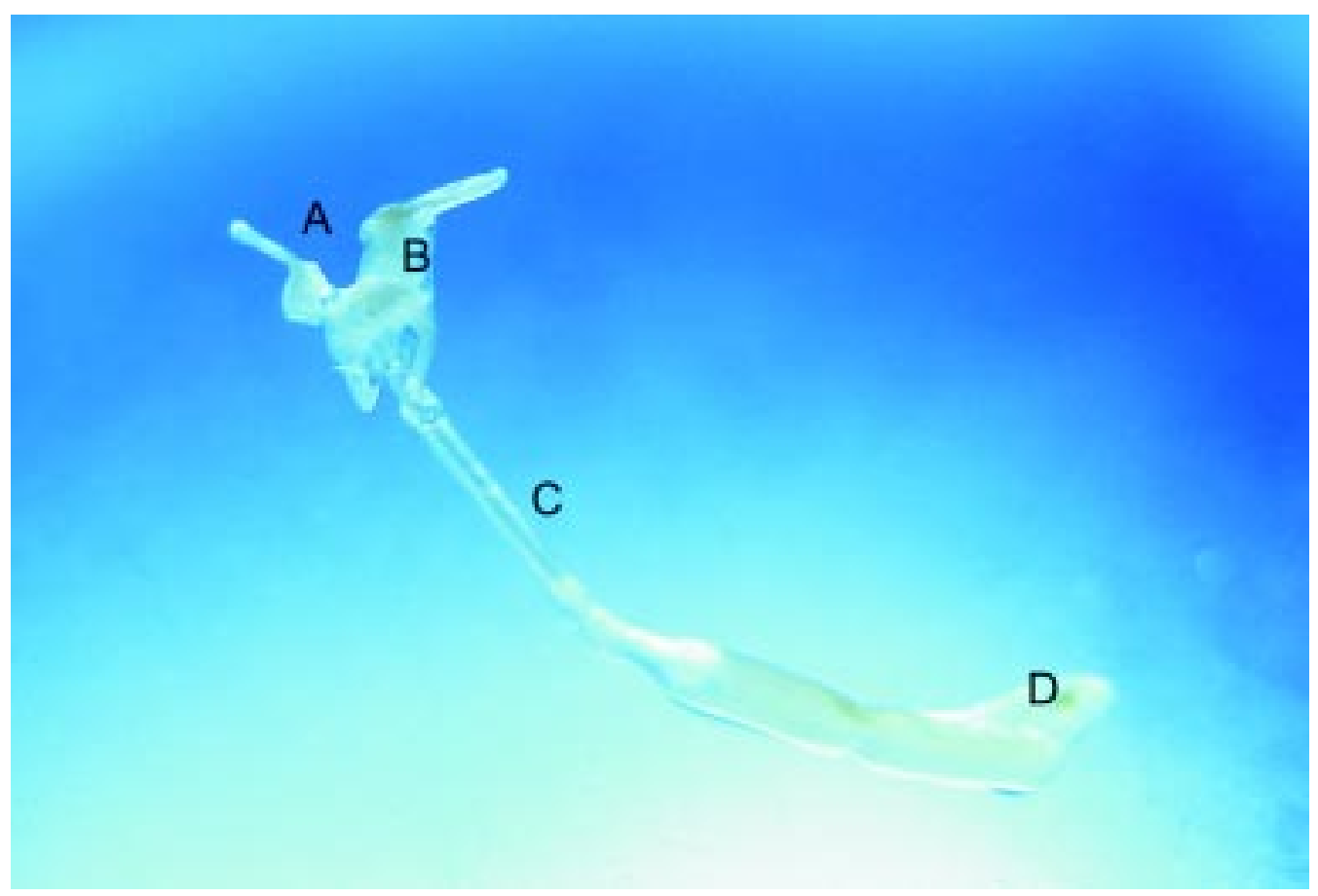

Figura 1. Lernaea cyprinacea. Processo de âncora para fixação (A); processo dorsal duplo, característica deste copépode (B); corpo com $0,7 \mathrm{~cm}$ de comprimento (C); porção caudal, onde estão inseridos os sacos ovígeros, não presentes nesta imagem (D). 
que contribuiu para a má aparência dos mesmos ao consumo humano. As áreas dorsal, caudal e nadadeiras dos peixes apresentaram maior prevalência parasitária.

\section{DISCUSSÃO}

Um trabalho recente, detectou pela primeira vez, a presença de lerniose no caracídeo nativo Astyanax bimaculatus do riacho Santo Antônio, bacia do rio Paraíba do Sul, estado de Minas Gerais [10]. Parasito identificado neste estudo, no sul do Brasil, no mesmo ano, o que mostra que o copépode apresenta-se distribuído nas diferentes regiões brasileiras.

A L. cyprinacea, também foi relatada em outros estudos, onde verificaram à presença do parasito em pisciculturas do estado de São Paulo parasitando peixes da espécie Piaractus mesopotamicus (Pacu) [11]. No verão de 2002, peixes da espécie Alosa alosa foram encontrados infectados com L. cyprinacea no rio Guadana no sudoeste da Espanha, sendo o primeiro relato deste parasitismo em seu ambiente natural [14]. A Companhia Integrada de Desenvolvimento Agrícola de Santa Catarina reporta o lambari como um dos hospedeiros da Lernaea sp. [15], dado este, comprovado neste estudo após a identificação do crustáceo nesta espécie de peixe.

A literatura relatou o parasitismo por L. cyprinacea pela primeira vez em Fundulus kansae (Cyprinodontidae), no verão de 1980, no Rio Prato Sul em Ogallala, Nebraska, sendo observado no trabalho que o parasito não teve preferência por sexo nos hospedeiros infectados com o copépode [1]. Resultado semelhante ao deste trabalho foi observado neste estudo, já que todos os peixes apresentavam o parasito na superfície do corpo.

O parasitismo de L. cyprinacea foi monitorado por pesquisadores em trutas arco-íris (Oncorhynchus mykiss) durante o período de 1981 a 1984 [3], sendo detectada primeiramente no verão de cada ano e mais abundantemente no outono, demonstrando homologia com este trabalho em que o parasitismo foi detectado nos meses de março e abril de 2006. As áreas dorsal e caudal dos peixes apresentaram maior prevalência parasitária, no entanto, além das áreas citadas anteriormente, os peixes possuíam o copépode nas nadadeiras laterais.

Conforme outros estudos, a resposta histopatológica ao parasitismo por L. cyprinacea em O. mykiss levou a granulomas infecciosos similares às lesões encontradas neste trabalho, os autores ainda citaram infecção secundária causada por bactérias do gênero Aeromonas nos rins de $45 \%$ dos peixes analisados [3].

De acordo com a literatura, a L. cyprinacea é um parasita de importância para a piscicultura, tanto economicamente, pela má aparência do peixe para o comércio, dado este observado no presente estudo, quanto ecologicamente, já que quando o parasito é introduzido no meio ambiente pode causar mortalidade nos peixes devido a infecções secundárias por fungos e bactérias [17]. A introdução intencional ou acidental de espécies exóticas é uma das maiores causas de perda da diversidade biológica, ao lado da destruição de habitats e da super exploração dos recursos naturais [12], no entanto, neste estudo, não se encontrou explicação para a infestação dos peixes no açude em Antonio Prado, já que não houve introdução de peixes exóticos no açude. Sugere-se que o parasito tenha sido incorporado no ambiente por aves migratórias.

\section{CONCLUSÃO}

Com base nos resultados, concluí-se que Lernaea cyprinacea é um parasito de peixes A. bimaculatus no Rio Grande do Sul, no qual causa lesões que ocasionam perda econômica aos criadores devido à má aparência dos peixes para o comércio.

\section{REFERÊNCIAS}

1 Adams A.M. 1984. Infestation of Fundulus kansae (Garmam) (Pisces: Cyprinodontidae) by the copepod Lernaea cyprinacea Linnaeus, 1758, in the South Platte River, Nebraska. American Midland Naturalist. 112: 131-137.

2 AZOPA - Associação dos Zootecnistas Do Paraná. 1999. Patologia de peixes, genética e melhoramento de peixes. Maringá: Coopergraf Artes Gráficas, pp.16-19.

3 Berry Jr. C.R., Babey G.J. \& Shrader T. 1991. Effect of Lernaea cyprinacea (Crustacea: copepoda) on stocked rainbow trout (Oncorhynchus mykiss). Journal of Wildlife Diseases. 27: 206-213.

4 Ferreira A. 2004. Ecologia trófica de Astyanax paranae (Osteíchthyes, Characidae) em córregos da bacia do Rio Passa Cinco, Estado de São Paulo. 56f. Piracicaba, SP. Dissertação (Mestrado Ecologia de Agroecossistema). Programa de Pós-graduação em Ecologia Animal, Universidade de São Paulo. 
5 Garcia A.M. \& Vieira J.P. 2001. O aumento da diversidade de peixes no estuário da Lagoa dos Patos durante o episódio El Niño 1997-1998. Atlântica. 23: 133-152.

6 Grabda J. 1963. Life cycle and morphogenesis of Lernaea cyprinacea. Acta Parasytology. 11: 169-198.

7 Harding J.P. 1950. On some species of Lernaea (Crustacea, Copepoda: Parasites of Freshwater Fish). Bulletin of British Museum.1: 1-27.

8 Humason G.L. 1979. Animal tissue techniques. 4th edn. San Francisco: W. H. Freeman and Company, 661p.

9 Kabata Z. 1985. Parasites and diseases of fish cultured in the tropics. London: Taylor \& Francis, 317p.

10 Magalhães A.L.B. 2006. First record of lernaeosis in a native fish species from a natural environment in Minas Gerais state, Brazil. Pan-American Journal of Aquatic Sciences. 1: 8-10.

11 Martins M.L., Onaka E.M., Moraes F.R., Bozzo F.R., Paiva A.M.F.C. \& Gonçalves A. 2002. Recent studies on parasitic infections of freshwater fish in the State of Sao Paulo, Brazil. Acta Scientiarum. 24: 981-985.

12 Oliveira M.D. 2004. Introdução de espécies: uma das maiores causas de perda de biodiversidade. Online. Disponível em: http://www.ibama.gov.br/pndpa. Acessado em 07/2006.

13 Pavanelli G.C. \& Eiras J. 1998. Patologia de peixes em pisciculturas no Brasil: Situação e Perspectivas Futuras. In: Resumos V Encontro Brasileiro de Patologistas de Organismos Aquaticos e I encontro Latinoamericano de Patologistas de Organismos Aquáticos (Maringá, Brasil). p.66.

14 Pérez-Bote J.L. 2005. First record of Lernaea cyprinacea (Copepoda: cyclopoida) on the allis shad. Folia Biologica. 53: 197-198.

15 Pizzolatti I.A. 2000. Lernaea cyprinacea controle e prevenção em pisciculturas de águas interiores. 48f. Lages, SC. Dissertação (Mestrado em Sanidade Animal). Programa de Pós-graduação do Centro de Ciências Agroveterinária, Universidade do Estado de Santa Catarina.

16 Pott V.J. \& Salis S. 2000. Relação de plantas coletadas pela Equipe Brasileira de Botânica durante a pesquisa do Aquarap1998 (equipe do Rio Negro). Conservation International. 4: 279-296.

17 Querol M.V.M., Querol E., Pessano E.F.C. \& Azevedo C.L.O. 2005. Ocorrência da carpa húngara, Cyprinus carpio (Linnaeus, 1758) e disseminação parasitária, no Arroio Felizardo, Bacia do médio Uruguai, Uruguaiana, RS, Brasil. Biodiversidade Pampeana. 3: 21-23.

18 Rogers W.A. 1968. The biology and control of the anchor worm, Lernaea cyprinacea. Fisheries Report. 5: 393-398. 